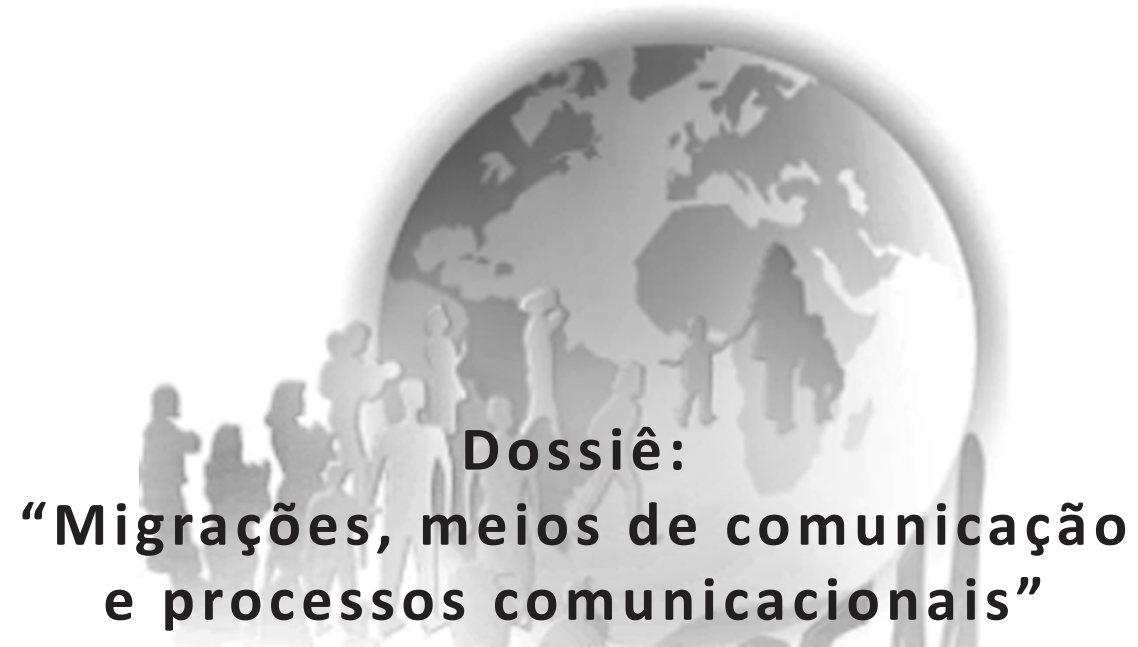

\title{
PROBLEMÁTICAS CONCERNIENTES A LA RELACIÓN COMUNICACIÓN-MIGRACIÓN
}

Pedro Russi ${ }^{1}$

La propuesta de este texto -que resulta de caminos de investigaciones ${ }^{2}-$, es colocar sobre la mesa de discusión algunos hilos que permitan tejer la relación entre comunicación y procesos migratorios. Eso será realizado considerando bases metodológicas para el estudio de esta interacción. Vale destacar que el objetivo no es presentar un modelo a seguir, sino compartir operaciones abiertas de sentido analítico. Para localizar la discusión, es un tema que me preocupa cuando se busca estudiar los procesos de migración, justamente por la necesidad de abrir pensamientos de abordaje más allá de los instrumentos metódicos. Ese

Universidad de Brasilia, Facultad de Comunicación. Brasilia, DF, Brasil.

2 RUSSI, Pedro. A midiatização como processo de construção das identidades culturais: estudo dos processos de produção de sentido - nas mídias impressas brasileira e uruguaias - das representações interculturais dos imigrantes no contexto do Mercosul; IDEM. As mediações nos processos comunicacionais da experiência de hetero-auto-experimentação no cenário das migrações contemporâneas do Mercosul - imigrantes uruguaios no sul do Brasil. IDEM. Reflexões (epistemológicas) A História Oral e Memória na pesquisa: "O midiático e não midiático na experiência hetero-auto-experimentação no cenário das migrações contemporâneas do Mercosul - imigrantes uruguaios no sul do Brasil"; RUSSI, Pedro, DUTRA, Delia. A dimensão comunicacional como recorte metodológico para o estudo das migrações; IDEM. A cidade e os migrantes: reflexões metodológicas. 
es el espíritu de las palabras que siguen, quiero decir, pensar juntos e inferir distintas posibilidades para dichas investigaciones. Considerando que el universo de este tipo de discusiones es amplio (nunca suficiente ni absoluto), dedico explícitamente el texto, dividido en tres tópicos, a los investigadores debutantes sobre el entendimiento de la relación comunicación-migración.

Palabras claves: comunicación, migración, medios de comunicación, investigación.

Propongo pensar sobre emigración e inmigración (de aquí en adelante: procesos migratorios), desde una perspectiva epistemológica y metodológica, que respondería a la pregunta, ¿de qué manera podemos también estudiar la relación comunicación-migración? Se trata más de un desafío en el sentido de pensar juntos, que de elaborar una respuesta finita; creo y puedo argumentar que lo interesante de este texto es la invitación a interactuar para poder conocer un fenómeno denominado como procesos migratorios.

En consecuencia, la discusión tiene como punto de partida la reterritorialización en la dinamización mediática, donde hay una desterritorialización que es configurada-propuesta por dichos dispositivos mediáticos, pero también por otras experiencias relatadas, donde se hacen visibles acciones concretas y abstractas de localización del sujeto. Este primer destaque ya nos coloca delante de una situación conceptual: la migración -como observaremos más adelante- no puede ser reducida a un movimiento corporal.

Sé que esto puede parecer repetitivo para algunos, pero entiendo que no está demás la redundancia ya que en diversas instancias todavía sucede esa confusión o, mejor, fusión entre migración y cuerpo. Lo que quiero establecer como punto de apoyo o de partida analítica, es ampliar el concepto de la migración incorporando procesos simbólicos que también dan sentido a esa vivencia. Lo simbólico no como aislado de lo concreto en sí, sino también como parte integrante de la experiencia de migración. Todo sujeto que emprende un proceso de migración, sea por la situación que sea, vivencia sueños, proyecciones, miedos... que se construyen a partir de narrativas y marcas mediáticas y no mediáticas, para delinear algunos sueños.

Las investigaciones realizadas, permiten inferir sobre los procesos comunicacionales -dinámicas comunicativas, vivenciales y mediáticas- de la experiencia migratoria. Eso posibilita entender las interacciones establecidas entre los individuos migrantes y la sociedad receptora, que puede ser receptora de un migrante que retorna. La elección de problematizar la migración desde esa perspectiva, es comprender la interacción simbólica de los procesos comunicacionales, que no pueden ser simplemente causa, sino también una forma de ser y estar. Así, se puede entender los procesos comunicacionales 
como siendo también configurados por la interacción entre los procesos de mediatización (materialidades y lógicas mediáticas, mediaciones mediáticas, p.ej., noticias vía periódicos...) y aquellos denominados como de materialidad no mediática (relatos de otros migrantes).

Por lo tanto, el desafío es comprender el lugar de los entretejidos y de las interacciones dramáticas (no sentido teatral-drama) en esa experiencia. Aquí explicito dos articuladores de las interrelaciones comunicacionales trabajados por Sodré ${ }^{3}$ en su libro Antropológica do Espelho. Uno, considerado como difusión ${ }^{4}$, que bien puede ser comprendido como mediático, es decir,

voltado para a relação ou o contato entre os sujeitos sociais por meio das tecnologias da informação, como imprensa escrita, rádio, televisão, publicidade, etc. Trata-se, portanto, do que se tem chamado de midiatização. Os dispositivos de veiculação (mídia) são de natureza basicamente societal. Em torno deles é que se tem articulado preferencialmente a maior parte dos estudos ou análises de Comunicação.

El otro, vinculación, que puede ser entendido como no mediático, entonces como de materialidad comunicativa en el sentido de

práticas estratégicas de promoção ou manutenção do vínculo social, empreendidas por ações comunitaristas ou coletivas, animação cultural, atividade sindical, diálogos, etc. Diferentemente da pura relação produzida pela mídia autonomizada, a vinculação pauta-se por formas diversas de reciprocidade comunicacional (afetiva e dialógica) entre os indivíduos. As ações vinculantes, que têm natureza basicamente sociável, deixam claro que comunicação não se confina à atividade midiática. A problemática do serem-comum ou das trocas simbólicas (...).

No podemos dejar de considerar que lo mediático también atraviesa (y es atravesado) como mediación en la vinculación. Obviamente que la idea no es buscar los aislamientos sino de cómo esas interrelaciones comunicativas interactúan en las formas (matrices) de comprensión de lo otro (alter). Así estaremos comprendiendo los acontecimientos de reconfiguración de los modos de estar juntos como transformación desde y sobre la concepción del otro,

en lugar de querer definir al otro (¿quién es él?), me vuelvo hacia mí mismo: ¿qué es lo que quiero, yo, que quiero conocerte? ¿Qué sucedería si decidiese definirte como una fuerza y no como una persona? Y isi me situase a mí mismo como otra fuerza frente a tu fuerza? Ocurriría esto: mi otro se definiría por el sufrimiento o el placer que me da. ${ }^{5}$

3 SODRÉ, Muniz. Antropológica do Espelho, p. 234.

4 Veiculação en el texto original - la traducción para difusión sería apropiada para el sentido propuesto por Sodré (ibidem).

5 BARTHES, Roland. Fragmentos de un Discurso Amoroso, p. 157. 
Es en ese sentido que podemos pensar el contacto entre (productos) mediáticos y no mediáticos, para ampliar el patrimonio de referencia culturalsimbólico por medio de tales productos, re-significando sentidos como re-localización del individuo al sondear, reconocer y entender el escenario en el cual se encuentra (o va a emigrar). De esa forma, articulará el conocimiento adquirido para elaborar y actualizar imaginariamente el nuevo espacio socialpúblico a ser experiemntado.

Es en este sentido, que podemos pensar como posible construir un gráfico ${ }^{6}$ mental para comprender las interrelaciones de la experiencia de migración, donde los procesos mediáticos, materializados en los diferentes dispositivos (sitios para migrantes, revistas, cartas, redes sociales-digitales, TV, radio, boletines...), son articulados con aquellos comprendidos como instancias de encuentros cuerpo-cuerpo (grupo familiar, barrio, escuela...). Por lo tanto, el desafío pasa por entender las diversas articulaciones de esos procesos comunicacionales y las matrices culturales de los sujetos -actuando como ángulos a partir de los cuales se lee y entiende el mundo-. Eso quiere decir, que al estudiar la especificidad migratoria (modos de subjetividades comunicativas), es vital inferir las formas de rediseñar y redinamizar las identidades de las geografías culturales puestas en interacción en el ambiente de la migración. Como ilustración, no es en la pregunta directa que tales especificidades o identidades se presentan, sino en los pequeños gestos de sentidos, signos muchas veces dejados de lados por parte de los investigadores, porque supuestamente son detalles diminutos. Pero es en ellos (en lo pequeño, el silencio, lo gestual...) donde se concentran los núcleos interpretativos que delinean el ambiente de inserción y recepción del otro, en la configuración de lo que podemos entender como autoconsciencia (endógeno) y consciencia cultural (exógeno) ${ }^{7}$.

Dicho de otra forma, el desafío analítico se concentra en las interacciones (macro-micro, mediáticas o no mediáticas) que diseñan las inferencias de los lugares de destino y de partida. A través de esas interpretaciones analíticas podemos hablar de sentidos de comunicación, ya que las mediaciones adquieren y dan sentidos a las culturas, configurando un destino y una salida -tanto como salida o retorno-. Entonces, el desafío interpretativo está no en catalogar las informaciones que los migrantes tienen, sino entender de qué maneras tales operadores de conocimiento sobre lo otro, se hacen presentes y se dinamizan a la hora de comprender "idónde estoy?".

Por ejemplo, si consideramos los medios, observamos que actúan como operadores entre varios o entre conjuntos de operadores simbólicos, porque el

\footnotetext{
${ }_{6}$ Proviene del sentido de grafo como relaciones lógicas de comprensión, líneas que relacionan lógicamente un punto con otro, no solamente como dibujo sino como expresión de sentido.

7 RODRIGO ALSINA, Miquel. Comunicación intercultural, p. 164.
} 
sentido explicitado a los lectores -por las noticias vehiculadas- es reorientado durante la circulación en los respectivos ambientes cultuales. Reconfigurando, así, el acontecimiento en un flujo continuo de reinterpretaciones, donde el cotidiano es reelaborado "en el cambio cultural que ellos catalizan y potencian: ese que conecta las nuevas difusas condiciones del saber (...) con las nuevas maneras de ver/narrar (...) y de ambos con las nuevos modos de estar juntos"8.

Se retoma aquí, como forma de ejercicio reflexivo sobre lo comunicacionalmediático, lo dicho al iniciar el texto, sobre las vivencias de desterritorialización y reterritorialización comprendidas y articuladas también desde los procesos mediáticos que no son ajenos a dos dominios de tensión-articulación: el mediático y el político. A los efectos de la temática y objetivo propuesto, como de las investigaciones que pueden ser elaboradas en el área, entiendo que tales dominios contienen el conflicto de: (i) desterritorialización mediática, representaciones que amplían el patrimonio cultural y simbólico; (ii) la reterritorialización mediática, de la cual el sujeto aprende, reconoce, entiende y conceptualiza el otro escenario para (re)localizarse; ambas en tensión con (iii) la territorialización política, en la cual los individuos no pueden entrar y trabajar libremente en los países deseados como "proyecto de vida" -limitados por procesos burocrático-costosos, por ejemplo "no es para todo el mundo".

Una sistematización de estos tres elementos ya posibilita la comprensión de la migración, bastante más allá de un pasaje de cuerpos por la frontera. Nos coloca en otra esfera interpretativa, donde los imaginarios juegan un papel fundamental para relocalizar los sentidos de territorios, ya no más geográficospolíticos, sino territorios de sentido. Esto se dibuja como un desafío inferencial para los estudios del área Comunicación sobre los procesos migratorios, donde indudablemente es necesaria la interdependencia de las ciencias, es decir, de los procesos interpretativos por parte de los diferentes saberes. En otras palabras, la comunicación no puede reducirse -al menos en estas temáticas, pero creo que en muchas otras- a lo que dicen los medios de comunicación. Es necesario comenzar a ahondar en otros operadores de sentidos sobre la dinámica migratoria, es decir, a entender aquello de que la comunicación es una relación entre consciencias, la conciencia no es, en definitiva, más que una red de vínculos entre los hombres, provocará Nietzsche en su aforismo 354 en De la Gaya Ciencia.

Entonces, la reterritorialización es vivida en sentido del conocimiento de lo otro, de la transformación de la cultura cotidiana, así en los medios también se encuentran la cultura-contenido que difunden y "en el cambio cultural que ellos catalizan y potencian: ese que conecta las nuevas difusas condiciones del saber (...) con las nuevas maneras de ver/narrar" ${ }^{\prime \prime}$. En consecuencia, se entiende que los

8 MARTIN-BARBERO, Jesús. Mediaciones urbanas y nuevos escenarios de comunicación, p. 163.

9 Idem. 
productos de los medios de comunicación son puestos en movimiento -por los individuos- como instrumentos para sondear (construidos y reconfigurados por la materialidad del uso) para el conocimiento del nuevo espacio social-público. Con ese objetivo los medios actúan como proveedores de 'imágenes' de la vida colectiva para ese nuevo escenario social de destino (ida-vuelta), en las cuales el individuo descubre otra realidad en la cual posiciona sus actos concretos e imaginarios ('proyecto de vida').

Es importante reforzar que no hay exclusividad de considerar absolutamente como único objeto de investigación los medios de comunicación y sus productos, sino, las dinámicas de sentido allí vehiculadas como acciones intermediarias que atraviesan el día a día colectivo e individual. A fin de que sean valorizadas las inclusiones y no las exclusiones, es importante comprender las mediaciones como espacios de conflicto,

[...] como dimensão de conflito social com suas resistências e rebeldias, com suas matrizes históricas, com suas realizações múltiplas que fabricam o mundo simbólico e material no dia-a-dia. A cultura na sua variedade étnica, regional, nacional, folclórica, popular, hegemônica e transnacional [.... $]^{10}$.

Por consecuencia, estudiar la memoria-que es comunicacional- permite recuperar los residuos que articulan las matrices culturales, para comprender básicamente las articulaciones de las informaciones por parte de los migrantes. Es decir cómo van produciendo sentidos de apropiación de lo próximo y lo distante. Así los individuos son entendidos, desde esta perspectiva, como esenciales en su historicidad, reformulando la sociedad y atravesándola por intermedio de sus acciones (complejas) ancoradas en aquellas matrices culturales transportadas entre los campos de interacción privados y colectivos. Quiero decir, los cotidianos-bienes-culturales ${ }^{11}$. Vemos, de esa manera, que no es en el dispositivo mediático o en la apropiación en sí de los productos, que se elaboran las referencias de interrelación del contexto vivenciado, sino en la dinámica y experiencia, significando lo vivido por los migrantes.

Por esa razón, estudiar lo comunicacional demanda trabajar las prácticas cotidianas de los sujetos, que muchas veces son puestas en las márgenes (simbólicas y materiales) por los discursos que centralizan en lo real simbólico -en acuerdo al statu quo-, una marginalidad de ser siempre el otro y nunca el nosotros. En las varias investigaciones de las que he participado, esa agenda se hace presente (nunca de forma categórica y evidente) en las narrativas de los migrantes desde el instante que deciden migrar, hasta en las acciones como proyectos de vida. Vale destacar que menciono narrativas y no respuestas, porque al decir narrativas estoy comprendiendo el encadenamiento lógico de un sentido entre lo dicho y no

\footnotetext{
${ }^{10}$ MALDONADO, Efendy. Da semiótica à teoria das mediações, p. 117.

${ }^{11}$ Ibidem, p. 108.
} 
dicho, obviamente algo que va más allá de la respuesta hablada a una pregunta mencionada. Ese es el detalle (no mínimo) que distingue las preguntas de un instrumento de manual-mecánico de investigación y la preparación de la entrevista con base epistemológica de lo que quiere ser comprendido sobre las migraciones. No es preguntar por preguntar, sino preguntar desde un sentido inferencial.

Hecho central cuando partimos de la base de que la migración es experiencia intrínseca a la condición humana y no puede, hoy, ser pensada fuera de los escenarios que la presentan y ofrecen al mismo tiempo como representacionesinterpretaciones sobre los movimientos humanos y sus consecuencias; donde se amplifica y dramatiza lo simbólico "del otro lado del muro". La comprensión sobre tales movimientos de sentido, depende de la formulación y entendimiento teórico epistemológico del investigador tanto sobre los medios de comunicación (procesos mediáticos) como de lo comunicacional en sí. Para eso es necesario, partir de un cuadro conceptual que permita realizar el análisis en el dominio de los hechos, necesarios para la representación y lugar de interpretaciones. Es visible de esa manera cómo los ejes epistemológicos y metodológicos, demarcan los análisis y discusiones.

Lo pensado anteriormente permite avanzar sobre las matrices analíticas y comprender la comunicación como eje en el escenario del migrante, por ejemplo, al desestabilizar los sentidos de lugar como espacio fijo y determinado en el interior de las geografías territoriales-nacionales. De esa forma, es posible inferir el tejido migrante-migración-extranjero también como múltiples espacios de vida que atribuyen sentidos y configuran simbólicamente a partir de lo comunicacional que puede ser mediático o no.

Por eso, la dimensión extranjero permite pensar incluso al sujeto que piensa emigrar, al convertir la migración en proyecto de vida pone en el horizonte el deseo (sueño) de desterritorialización. En esa perspectiva analítica, el individuo puede ser extranjero sin nunca haber salido del lugar de "origen", porque al considerar las interacciones allí propuestas el sujeto vive la experiencia de ser extranjero en "su" escenario. De esa manera, nos deparamos con la necesidad de comprender los procesos migratorios también desde esa perspectiva simbólica, por lo tanto de sentido que configura una forma de leer el aquí desde allá. Podemos observar lo territorial de fronteras físicas totalmente desfigurado, sin movimientos corporales atravesando muros. Esto nos coloca un desafío, el de proponer estudios de esta migración que no es simplemente imaginaria, sino que se explicita en formas de ser y estar, en maneras de apropiación del cotidiano, de las interacciones y las relaciones intersubjetivas que se construyen, teniendo en muchas ocasiones implicaciones en la salud mental del individuo. No es una preocupación menor y lejos de la comunicación comenzar a considerar estas 
migraciones que podemos denominar "sin cuerpo", es posible citar aquí como forma de ejemplo, la matrices comunicacionales estudiadas por la Escuela de Palo Alto (Colegio Invisible) -para destacar una-.

Aquí podemos hacer el puente para otro operador de sentido, me refiero a la posición de individuo en el colectivo de llegada (sociedad "receptora"12), ya que parece determinada por el hecho de no haber pertenecido a ese colectivo desde el inicio o de no pertenecer a las matrices de un nosotros a partir de atributos configurados originalmente fuera del colectivo ${ }^{13}$. El extranjero no tiene más tierra ("mi tierra donde nací"), porque se "esparce" en el acto de que "toda la tierra es mi tierra, ser ciudadano del mundo, no tener fronteras...", mucho más allá de que tales expresiones (frases consuelo) entren en conflicto con las políticas de clausura de fronteras.

Reflexionar sobre ese movimiento proporciona una "mirada de extranjero", por lo tanto, en ese punto se torna importante reflexionar sobre los procesos comunicacionales que entran en juego para el reconocimiento del otro.

Con la intención de profundizar en ese punto, podemos retomar la memoria -que mencionamos anteriormente- como operador dinamizador de la relación antes-durante-después de la migración, para entender la capacidad transformadora de estructuras comprensivas del individuo en ese contexto de desplazamientos. Como sugiere Todorov ${ }^{14}$,

...la memoria no se opone en absoluto al olvido. Los dos términos para contrastar son la supresión (el olvido) y la conservación; la memoria es, en todo momento y necesariamente, una interacción de ambos. El restablecimiento integral del pasado es algo por supuesto imposible (pero que Borges imaginó en su historia de Funes el memorioso) y, por otra parte, espantoso; la memoria, como tal, es forzosamente una selección: algunos rasgos del suceso serán conservados, otros inmediata o progresivamente marginados, y luego olvidados. (...) un rasgo constitutivo de la memoria, esto es, la selección.

Porque la memoria tiene un lugar para poder comprender los procesos comunicacionales de las interacciones entre el migrante y la cultura receptora. ¿Cuál es ese lugar? El de ser entendida como medio para la exploración del pasado y no como mero instrumento para recordar. De esa manera, aludo a aquella dinámica propuesta por Benjamin ${ }^{15}$ de "cavar y recordar", compartiendo con él la convicción de que la memoria,

é o meio onde se deu a vivência (...) Quem pretende se aproximar do próprio passado soterrado deve agir como um homem que escava. (...) não deve temer

\footnotetext{
${ }^{12}$ Las comillas en "receptora" son de propósito, porque no siempre hay una recepción stricto sensu.

13 SIMMEL, Georg. O estrangeiro, p. 182.

${ }^{14}$ TODOROV, Tzvetan. La memoria amenazada, p. 3.

${ }^{15}$ BENJAMIN, Walter. Rua de mão única, p. 239.
} 
voltar sempre ao mesmo fato, espalhá-lo como se espalha a terra, revolvê-lo como se revolve o solo. (...) Ou seja, as imagens que, desprendidas de todas as conexões mais primitivas, ficam como preciosidades nos sóbrios aposentos de nosso entendimento tardio, igual a torsos na galeria do colecionador.

Por tal motivo corresponde y se puede hablar de recuerdos y resignificación por las apropiaciones e intervenciones comunicacionales (mediáticas y no mediáticas) en el cotidiano del migrante para tornar familiar lo que le es extraño. En esa interacción se materializan las dinámicas de lectura de las informaciones vehiculadas en cualquiera de esos ámbitos de comunicación.

Se levamos eso en consideración para avanzar en una investigación debemos preguntarnos: ¿qué se entiende por matrices culturales? Son las referencias y dinámicas de identidad que resultan del mantenimiento, articulación, entrelazamiento, combinaciones, tensiones y rediseños de repertorios y experiencias que nos tornan sujeto. Estudiar las matrices culturales significa introducir el tema en el espacio donde se articulan los sentidos y procesos de interacción, incidiendo en las representaciones individuales y colectivas. O sea, en marco del discurso mediático, sería lo que Verón llama de "operadores semánticos", pues "reemplazan interpretaciones que no se explicitan y análisis que no se formulan..."16.

Continuando en esa idea, los medios de comunicación, como estructura y lógica de producción, van a presentar las interrelaciones en las lógicas y procesos que los caracterizan como dispositivos mediáticos. De esa forma, las distinciones entre condiciones reales y condiciones representativas-interpretativas se tornan más tenues y complejas $^{17}$. Los diferentes medios de comunicación se tornan lugares donde se elaboran, negocian y difunden discursos, valores que actúan como mediaciones en los procesos de sociabilidad mediatizada. La interacción es también especificada desde el material mediático, por lo tanto, articulada a sus formas de comprender y prender las interacciones entre lo individual y colectivo. Es de esa manera que se institucionaliza el proceso, ya que las gramáticas que permiten el intercambio simbólico, que se puede considerar de «antropológico», no surgen del espacio, del imprevisto y sí de lo pensado, medido en el esqueleto mediático. Esta comprensión, sobre el fenómeno migratorio, se torna central nos días actuales (2016, inicio del S.XXI), ya que es necesario elucidar en las lógicas narrativas y discursivas una única y determinada calidad de migrar: la que responde al statu quo en contraposición a la que está fuera del sistema y deberá ser eliminada física y simbólicamente. Creo que es en ese plano que hoy se establece la narrativa

${ }_{16}$ El modelo y esquema propuesto por Eliseo VERÓN (medios, actores individuales e instituciones), a pesar de ser simple (esquemáticamente) permite pensar la complejidad de los fenómenos de la mediatización y ayuda en el proceso de análisis. Cf. Esquema para el análisis de la mediatización, 1997.

${ }^{17}$ COGO, Denise. Mídia, migrações e interculturalidade. 
mediática sobre las migraciones -algo que demanda otra abertura reflexiva que no puede ser contemplada aquí por una cuestión de espacio y objetivo-.

$$
* * *
$$

Ya caminando hacia las líneas finales, y pensando en el destinatario de este texto, podemos entender que la investigación sobre migración-comunicación necesita asumir como eje de comprensión, las experiencias simbólicas de conflicto y de gestión, por parte de los migrantes, considerando las matrices que posibilitan abarcar las instancias comunicacionales como dimensiones de proyección, retrospección y actualidad. Así, podemos entender cómo las narrativas de los migrantes, revelan los imaginarios implicados en la arquitectura y acción discursiva que delinean (no determinantemente) dicha experiencia.

Es importante, en el sentido metodológico, tener clareza de que dichas narrativas no pueden ser entendidas como si el mundo le hablara directamente al investigador, eso lo que anularía el proceso científico de la investigación. El proceso analítico se torna científico cuando alberga la vigilancia epistemológica (bachelardiana), rompiendo los obstáculos de esa índole -salir de la experiencia inmediata y directa o de las primeras impresiones-, en busca de reflexiones que construyen el conocimiento desde las inferencias. Por eso no es la respuesta directa a la pregunta directa que nos dirá lo que es la experiencia de la migración, el investigador deberá entender otros índices y pistas que le permitirán elaborar interpretaciones más allá de lo explicitado por el entrevistado. Llamar la atención sobre esta situación es central porque podemos encontrarnos -como nos ha sucedido- con grandes reportajes o interesantes descripciones, pero no con trabajos analíticos de fondo que permitan en futuras investigaciones entender a fondo - dentro de lo posible- lo que es la relación comunicación-migración.

En efecto, trabajar con un universo específico de migrantes permite captar mejor los procesos que serán analizados, para romper el paradigma muchas veces construido por los discursos mediáticos- de que la migración es un mero desplazamiento físico. Por eso la posibilidad de avanzar en el análisis de la configuración mediática y no mediática de la migración, que se enfrenta a diferentes ofertas (mediáticas o no) proponiendo interacciones y apropiaciones sobre lo distinto. Son vivencias que conforman arenas en múltiples direcciones, paradojas discursivas y de acentuación.

El desafío es poder entender, a través de esas vivencias, los flujos y contraflujos como espacios dinámicos donde los sujetos elaboran, negocian y difunden sentidos y valores. Para que, de esa forma, podamos entender los cruzamientos por los cuales los individuos se reconocen, sondan sentidos y elaboran un colectivo. Eso quiere decir, entender los procesos para preguntarnos... ¿Qué migración es esa? 


\section{Bibliografía}

BARTHES, Roland. Fragmentos de un Discurso Amoroso. Madrid: S XXI, 1993.

BENJAMIN, Walter. Rua de mão única. Obras Escolhidas II. São Paulo: Brasiliense, 1997.

COGO, Denise. Mídia, migrações e interculturalidade. São Leopoldo: PPGCOMUnisinos/CNPq/Fapergs (relatório de pesquisa), 2002.

FAUSTO NETO, Antônio. Comunicação e mídia impressa. Estudo sobre a AIDS. São Paulo: Hacker Editores, 1999.

MALDONADO, Efendy. Da semiótica à teoria das mediações. In MELO, José Marques de (org.). Comunicação, cultura, medicações: o percurso intelectual de Jesús MartínBarbero. São Bernardo do Campo: Umesp, 1999, p. 113-132.

MARTIN-BARBERO, Jesús. Mediaciones urbanas y nuevos escenarios de comunicación. In BELTRAN, L. Ramiro (org.). Comunicación y espacios culturales en América Latina. Cátedra de la UNESCO de Comunicación Social, 1994, p.151-165.

MOUILLAUD, Maurice; PORTO, Sérgio D.; DUARTE, Adriano R. et alii. O jornal. Da forma ao sentido. Brasilia: Paralelo 15, 1997.

RODRIGO ALSINA, Miquel. Comunicación intercultural. Barcelona: Anthropos, 1999.

RUSSI, Pedro. A midiatização como processo de construção das identidades culturais: estudo dos processos de produção de sentido - nas mídias impressas brasileira e uruguaias - das representações interculturais dos imigrantes no contexto do Mercosul. XXV Congresso Brasileiro de Ciências da Comunicação. Salvador: Intercom/UNEB, 2002.

RUSSI, Pedro. As mediações nos processos comunicacionais da experiência de heteroauto-experimentação no cenário das migrações contemporâneas do Mercosul imigrantes uruguaios no sul do Brasil. XXVIII Congresso Brasileiro de Ciências da Comunicação. Rio de Janeiro: Intercom/UERJ - Universidade do Estado do Rio de Janeiro, 2005.

RUSSI, Pedro. Reflexões (epistemológicas). A História Oral e Memória na pesquisa: "O midiático e não midiático na experiência hetero-auto-experimentação no cenário das migrações contemporâneas do Mercosul - imigrantes uruguaios no sul do Brasil". Encontro Catarinense de História Oral - SC/Joinville; Universidade da Região de Joinville - UNIVILLE /Departamento de História, 2005.

RUSSI, Pedro; DUTRA, Delia. A dimensão comunicacional como recorte metodológico para o estudo das migrações. Revista Latinoamericana de Comunicación Chasqui, v. 1, 2014, p. 4-12.

RUSSI, Pedro; DUTRA, Delia. A cidade e os migrantes: reflexões metodológicas. In SODRÉ, Muniz et alii. Diásporas urbanas. Migrantes, viajantes e transeuntes. Goiânia: UFG, 2015, p. 171-195.

SIMMEL, Georg. O estrangeiro. In MORAIS FILHO, Evaristo de (org.). Georg Simmel: sociologia. SP: Ática, 1983, p. 182-188.

SODRÉ, Muniz. Antropológica do Espelho. Petrópolis-RJ: Vozes, 2002.

TODOROV, Tzvetan. La memoria amenazada. Disponible en: <www.cholonautas. edu.pe> (Ciencias Sociales) [07/08/2005]. 
TRIGO, Abril. Memorias migrantes. Testimonios y ensayos sobre la diáspora uruguaya. Mdeo.: Trilce, 2003.

VERÓN, Eliseo. Esquema para el análisis de la mediatización. Diálogos de la comunicación, Lima, n. 48, 1997, p. 9-16.

\section{Abstract \\ Issues concerning the relationship communication-migration}

The purpose of this text, which is the result of the research, is to raise some discussion topics to allow weaving the relationship between communication and migration processes. This will be done considering methodological basis for the study of this interaction. It should be noted that the aim is not to present a model to be followed, but open sharing of analytical sense operations. To find the discussion, it is an issue that concerns me when it seeks to study the migration processes, precisely because of the need to open thoughts approaches, beyond the methodological tools. This is the spirit of words that follow, that is, think together and infer various possibilities for such investigations. Considering that the universe of these types of discussions is broad (never sufficient, or absolute), I explicitly dedicate the text, divided in three topics, to the debutant researchers in relation to the understanding of the relationship between communication and migration.

Keywords: communication, migration, means of communication, investigation.

Recibido para publicación en 22.03.2016

Aceptado para publicación en 26.04.2016 Received for publication in March 22 $2^{\text {th }}, 2016$ Accepted for publication in April 26 $6^{\text {th }}, 2016$

ISSN impresso: 1980-8585

ISSN eletrônico: 2237-9843

http://dx.doi.org/10.1590/1980-85852503880004602 